\title{
"I'm a fat bird and I just don't care": A corpus-based analysis of body descriptors in plus-size fashion blogs
}

\section{Hanna Limatius}

\begin{abstract}
Plus-size women have traditionally been, and continue to be, in a marginalized position in contemporary Western societies. This marginalization is especially visible in the field of fashion, since mainstream fashion media promotes thinness as the bodily ideal for women. However, the field of fashion is slowly but surely becoming more diverse in its representation of beauty. Fashion blogs, along with other social media platforms, are instrumental to these changes. Through blogging, plus-size women can actively participate in constructing new fashion discourses, as well as forming communities around their shared interest in fashion. One way of reconstructing the hegemonic discourses built around fashion and being plus-size is the reappropriation of words used to describe the plus-size body, such as "fat". In this article, I apply corpus-linguistic methodology to investigate the role of body descriptors in twenty UK-based, plus-size fashion blogs. The frequency and distribution of forty-five terms that are used to describe a plus-size woman's body in a selfcompiled blog corpus are discussed alongside qualitative examples from blog texts. The results of the study reveal the variety within the genre of plus-size fashion blogs: fat acceptance activism influenced bloggers use certain body descriptors more than bloggers who focus on fashion trends and personal style. The study highlights the importance of combining qualitative and quantitative methods in research on online communities.
\end{abstract}

Keywords: corpus linguistics, community of practice, fashion blogging, fat acceptance movement, identity, marginalization, online community.

\section{Introduction}

In this article, I investigate the language use of plus-size women who write fashion-focused blogs. More specifically, the study explores the variety of terms these bloggers use to describe their (and other plus-size women's) bodies in their blogs. Following LeBesco (2001, p. 77), I believe that studying the language fat people ${ }^{1}$ use will help us understand the shifting discourses around fatness, identity, and the body. Language can be seen as a key player in the "revolution" (LeBesco, 2001, p. 76) against the negative and highly medicalized perceptions of fatness rooted in contemporary Western culture. As previous studies on plus-size women and identity (e.g. Gurrieri \& Cherrier, 2013; Downing Peters, 2014; Harju \& Huovinen, 2015; Limatius, 2017) have demonstrated, body descriptors have an important role when it comes to identity construction.

The use of body descriptors is also one part of the shared repertoire (cf. Wenger, 1998) of the blogging community. The bloggers in the present study belong to a larger collective of plus-size

In this article, the words "fat" and "plus-size" are both used as descriptors for the bloggers under investigation. Following the example of the bloggers themselves, these terms are used as neutral descriptors with no derogatory intent. 
women who blog about fashion, often referred to as the fatosphere in earlier literature (e.g. Harju \& Huovinen, 2015, p. 1603; Gurrieri \& Cherrier, 2013, p. 279). As the bloggers I investigated interact with each other regularly, express shared goals and have developed community-specific routines and behaviors, the social group they have formed can be viewed as a community of practice (e.g. Wenger, 1998).

The present study explores a corpus compiled from 20 UK-based plus-size fashion blogs. I examine the frequency and distribution of 45 body descriptors that appear in public blog texts as well as the commenting sections of the blogs. I also investigate the differences between three sub-categories of bloggers within the group: fat activists, fashionistas and all-rounders. Some plus-size fashion bloggers identify with social movements such as the fat acceptance movement (Scaraboto \& Fischer, 2013; Afful \& Ricciardelli, 2015) and the body positivity movement (Sastre, 2014), while others emphasize mainly fashion-focused content, with little sociopolitical engagement.

I seek to answer the following research questions:

1) What kind of body descriptors do plus-size fashion bloggers use?

2) How much variation exists in the use of body descriptors within the blogging community?

3) What differences are there in the use of body descriptors between blog texts and commenting section discussions?

4) In what ways does the use of body descriptors reflect identity construction?

I will begin by discussing the plus-size fashion blogging phenomenon and how it relates to the social marginalization of bigger women, as well as the role of positive identity construction through blogging, with an emphasis on body descriptors. Following the discussion on plus-size fashion blogging, I will focus on the concept of a community of practice (e.g. Wenger, 1998; Holmes \& Meyerhoff, 1999) and the ways in which the blogging community under investigation in the present study functions as such a community. After that, I will discuss previous corpus-linguistic and corpus-aided studies of online communities, highlighting the benefits of a corpus-based approach. In the data and methods section, I will explain the process of corpus compilation as well as my analytical approach. Lastly, the results of the study are presented, followed by a discussion and concluding remarks.

\section{Plus-size women, identity and language}

The idolization of thinness is deeply rooted in contemporary Western culture, especially when it comes to women. According to Hartley (2001, p. 62), large female bodies are presented as "unfeminine", and "treated with derision in our society" - men, who are traditionally allowed to "take up more space" than women, do not face such strict judgement for being fat. Harjunen (2009, p. 29) also underlines the role of gender in size-based marginalization; according to her, (straight) male bodies are generally not objectified and sexualized to the same extent as women's bodies, and body size does not define men's social acceptability in the same way as it does for women. However, both Harjunen (2009, p. 27) and Hartley (2001, p. 67) mention that gay men also face strict beauty standards; thus, those who are objectified by the male gaze are more likely to be discriminated against for being fat. ${ }^{2}$

2 We should, however, note that modern Western media presents unattainable beauty goals for all gender identities and sexual orientations. 
Fatness is also a characteristic that can be openly criticized, unlike many other features of a person's appearance; Hartley (2001, p. 65) names fat-phobia as "one of the few acceptable forms of prejudice left" in Western societies. The mainstream media's construction of an obesity epidemic discourse, where fatness is presented as a medical and economical strain on society, but the blame for it is nevertheless placed on the individual (Dickins et al., 2011), is a relevant example of the systematic marginalization of fat people.

In the world of fashion, the societal prejudices against fatness are even more pronounced (Scaraboto \& Fischer, 2013). Even though contemporary fashion can be argued to be changing and becoming more diverse, thin bodies still dominate mainstream fashion imagery (Connell, 2013). Against this background, fashion blogging, i.e. authoring a blog that is focused on the presentation of the individual style of the blogger, and/or reviews of current fashion trends, can offer women with marginalized bodies new ways of participating in fashion discourse (Rocamora, 2011, p. 421), or, more importantly, constructing counterdiscourses (Connell, 2013) to traditional fashion media. As earlier studies have shown, for plus-size women in particular, blogging about fashion can be an empowering experience that enables the construction of a positive identity (Gurrieri \& Cherrier, 2013; Harju \& Huovinen, 2015; Limatius, 2017).

Language is in a key role in the formation of this identity. As LeBesco (2001, p. 76) states, "language can be used to carry out the revolution that replaces the spoiled identity of fatness." According to LeBesco (2001, pp. 76-77), fat people can use the power of words - spoken and written - to reconstruct their identity, which is why it is important to examine the terms that fat people use to describe themselves. As LeBesco (2001, p. 77) states, the use and reapproriation of (traditionally negative) terminology can be considered a strategy for "talking one's way into a subject position"; the way fat people construct their identity through self-descriptive terms has the potential to redeploy and destabilize dominant discourses. Considering their focus on personal narratives (Titton, 2015; Limatius, 2017), fashion blogs are suitable material for investigating the use of these terms.

Previous research on the language of plus-size fashion bloggers has mostly focused on the role of the word "fat". Harju and Huovinen (2015, p. 1612) discuss reappropriating "fat" as a way for plussize women to (re)construct their identities as empowered subjects. Similarly, Scaraboto and Fischer (2013, p. 1239) refer to fat acceptance activists, including (but not limited to) bloggers, contesting the negative connotations of the word. This process is comparable to the reappropriation of derogatory terms within other marginalized communities, such as the black community (Allan, 2015, pp. 189-190), and the LGBTQ+ community (Kelsey, 2009).

However, as LeBesco (2001, p. 77) states, fat acceptance activists have differing opinions about the ways in which the discourses surrounding fatness and the body can be redefined; while some wish to "be able to make claims on behalf of all fat people", others want to focus on their individual experience and "speak for themselves". Bloggers who focus less on fat acceptance and more on presenting fashion may prefer other terms than "fat", but perhaps do not use body descriptors in general as often as activism-driven bloggers. Moreover, within the fashion industry, "plus-size" is generally used more than "fat", and thus considered appropriate and "neutral" by many bloggers (Limatius, forthcoming 2019). Brands that offer larger sizes also tend to include "flattering" terminology that has connotations to femininity, such as "curvy/curves/curve" or "voluptuous", in the names of their clothing lines. ${ }^{3}$ 
There is variation within the plus-size blogosphere, just like there is variation within the fat acceptance movement, which is why I consider it important to study a wide range of body descriptors and their relationship to identity construction. ${ }^{4}$ Even though LeBesco (2001, p. 77) expressed "a need to examine more closely the range of terms used and reappropriated by fat people" almost twenty years ago, systematic investigations of such terms have not been done before.

\section{Blogs as communities of practice}

One theoretical concept that is useful in studying the role of body descriptors within the group of bloggers is the community of practice (Lave \& Wenger, 1991; Wenger, 1998). Following Wenger (1998), three characteristics that define a community of practice can be distinguished: mutual engagement (e.g. interacting with other bloggers on a regular basis), a joint enterprise (e.g. a common goal of reconstructing fashion discourse), and a shared repertoire (a collection of resources, including linguistic features, that characterize the interaction of the group). Specific ways of using body descriptors within the blogging community - such as the reappropriated "fat" - fall within the shared repertoire of the group.

One of the key features of a community of practice is the fact that becoming a community member involves a process of learning (Holmes \& Meyerhoff, 1999, p. 174). A new blogger might be familiar with the practices of plus-size fashion bloggers if she has been a reader of this genre of blogs for a long time; however, it will take time for her to truly immerse herself in the community and to learn how group-specific meanings are constructed in interaction. A community of practice is defined both by its members and the practices these members engage in (i.e. who the members are, and how the members act within the community) - thus, as the community develops and new members join, the practices and behaviors that are considered characteristic of the community also evolve (Eckert \& McConell-Ginet, 1992, p. 464). A particular body descriptor can have an empowering meaning within the community at a specific point in time, but this meaning may shift along with changes that take place in the context of the community. The community members constantly engage in processes of negotiating the meanings of specific terms.

A community of practice tends to have core members and peripheral members (Wenger, 1998), as some members have a more established role within the community, while others might be newcomers, or simply choose to be less active. In the case of the present study, blog readers who comment on blogs but do not author their own blogs could be considered peripheral members, and the bloggers themselves also display different levels of engagement with the community - for example, some bloggers post less frequently than others.

\section{Corpus-based approaches to studying online discourse}

The field of corpus linguistics offers methodological tools for collecting and analyzing large datasets of language (Drasovean \& Tagg, 2015). In corpus-assisted or corpus-aided discourse analysis, corpus-linguistic methods are used to identify keywords and recurring patterns in corpora, illustrating whether a discursive feature identified in a qualitative analysis extends to a larger

$4 \quad$ Of course, in addition to textual practices, bloggers use visual means such as "outfit of the day" photographs to construct their identities (cf. Harju \& Huovinen, 2015). 
amount of texts and/or speakers (Drasovean \& Tagg, 2015). A corpus-based approach complements qualitative research by avoiding the danger of cherry-picking and producing results that are more easily reproduced (McDonald \& Woodward-Kron, 2016, p. 158).

Corpus-linguistic methods have been utilized in studying the language use in various digital media, including TED Talk videos (Drasovean \& Tagg, 2015; Mattiello, 2018), YouTube comments (Ivković, 2013), Tumblr blogs (Bourlai, 2018), and Twitter (e.g. van der Bom et al., 2018; Zappavigna, 2014; Sifianou, 2015). While blogs in general are popular material for different types of corpus-based studies (e.g. Kehoe \& Gee, 2012; Lutzky \& Kehoe, 2016; Lutzky \& Kehoe, 2017; Lehti \& Laippala, 2014), previous research on fashion blogs consists mainly of ethnographic case studies of small data-sets. As such, the present study brings a new perspective both to the study of the fashion blogging phenomenon in general, and plus-size fashion blogs in particular.

An online group's expressions of community and shared identities can be reflected in quantitative data in various ways. Bourlai (2018, p. 54), for example, found that Tumblr users who participated in fan communities ("fandoms") used certain tagging practices frequently. It could be theorized that the members of the fandoms expressed their membership by following the "rules" of tagging within the existing community (Bourlai, 2018, p. 48). Twitter hashtags had similar community- and identity-constructing functions in Zappavigna's (2014) study of the CoffeeTweets corpus. Zappavigna (2014, pp. 152-153) discovered two types of identities of coffee drinkers on Twitter: Coffee Connoisseurs and Coffee Addicts. The former discuss coffee in a context of quality and appreciation, while the latter identify it as a necessity, which shows in the use of hashtags such as \#ineedmorecoffee (Zappavigna, 2014, p. 154).

McDonald and Woodward-Kron (2016) compared the language of long-term members and newcomers in an online support group for people living with bipolar disorder. They discovered, among other things, that long-term members used an "I would + adjunct" construction (e.g. "I would strongly suggest that you discuss it with your pdoc") when giving advice to newer members, thus "highlighting their shared role as people living with bipolar disorder" (McDonald \& WoodwardKron, 2016, p. 165). Additionally, those who had been members for a longer time used communityspecific jargon more, and constructed a shared identity with other users on the board, whereas newer members tended to make a division between their individual identities and the online community (McDonald \& Woodward-Kron, 2016, pp. 167-169).

In the present study, I view body descriptors as markers of identity. By describing their bodies in specific ways, plus-size fashion bloggers can communicate how they wish to be seen and what kind of terms they identify with. Similarly, choosing to not use a certain term, or using it in negative contexts, can signal the blogger's wish to dissociate herself from that term. Body descriptors can also be used to index group membership - for example, the use of the word "fat" as a self-descriptor continuously and on purpose can be interpreted as the blogger aligning herself with the values of the fat acceptance movement.

\section{Data and method}

\subsection{Compiling the corpus}

Corpus-linguistic or corpus-aided studies of blogs are often based on large corpora such as the Birmingham Blog Corpus (Kehoe \& Gee, 2012; Lutzky \& Kehoe, 2017). The blog corpora that have been compiled by the researchers themselves for specialized studies tend to be relatively small 
and contain randomly chosen blogs that focus on a specific area of interest or are authored by people who fit certain criteria. For example, Lehti and Laippala's (2014) corpus of French politicians' blogs consisted of roughly 700,00 words, and the researchers utilized blogs that were "found using web search engines and through links displayed in blogs already found." Lukač (2011), who studied pro-eating disorder blogs, also used a search engine to locate blogs centered around a particular theme; blogs that were found as a result of a Google search for "pro-ana" were included in a corpus of 222,464 words.

The premise of the present study is somewhat different from both types of previous studies. Instead of studying blogging as a phenomenon, or blogs that simply share a similar topic, the blogging community I investigate already existed as a network of bloggers who followed and interacted with each other at the time of corpus compilation. Since blogging can be characterized as a "journey" (Limatius, 2017), and blogs change and evolve over the years, I wanted to include all textual material that had been posted in the blogs since the beginning of each individual blog. The corpus was compiled specifically for this project.

The first stage of corpus compilation took place in January 2015, when I contacted 35 members of a private Facebook group called \#PSBloggers - For Bloggers Only. At the time, the group had roughly 140 members, and I chose bloggers based on the following criteria: 1) they had blogged actively in 2014, 2) the language of their blogs was English, and 3) their blogs featured comments from readers. I sent the bloggers an email where I asked for permission to use their blog texts in my research, and twenty of them gave their consent. ${ }^{6}$ I did not include any of the blogs whose authors did not respond to my email in the corpus. The finished corpus consists of all blog texts and comments that had been published in the 20 blogs before January $1^{\text {st }}, 2015$. All 20 blogs included in the corpus were authored by UK-based women who identified as plus-size. The blog texts and comments were downloaded into an online database which is hosted on a password-protected, personal server. The data is stored in a way that allows me to search the corpus without the aid of separate corpus-linguistic software.

The corpus contains 7,776 blog posts $(3,177,959$ words) and 32,737 comments $(1,000,049$ words). Figure $1^{7}$ below illustrates the number of blog posts and the number of comments in each blog, as well as the number of words in posts and comments in each blog. For ease of analysis, and to protect the bloggers' privacy, each blog has been randomly assigned a number from one to twenty as an identifier (Blog 1, Blog 2, etc.)

\footnotetext{
$5 \quad$ As a blogger myself, I was already a member of said Facebook group at the time.

$6 \quad$ There are no set ethical guidelines to the use of blog material in research; some researchers consider any public online material that does not require registration appropriate to use without asking for permission, while others are of the opinion that the blogger needs to be notified. I personally wanted to obtain informed consent from the bloggers whose blogs I studied.

7 I would like to thank my Jukka Tyrkkö for his help in designing the visualizations of data for the present study.
} 
Figure 1: The number of posts, comments and words in the corpus

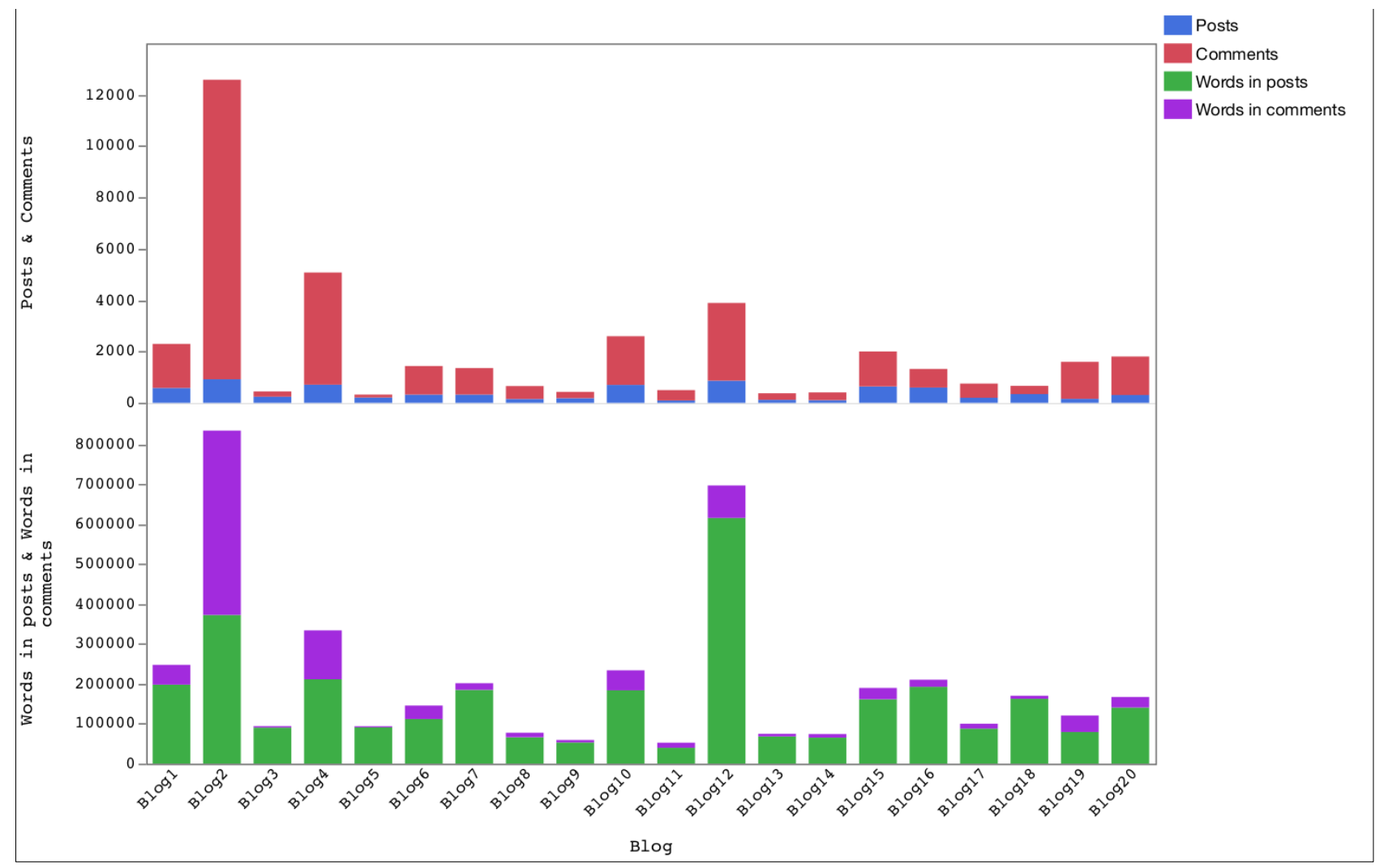

\subsection{Analyzing the corpus}

I compiled a list of all descriptors for plus-size bodies in the corpus by using the Word List function in AntConc Version 3.4.4 (Anthony, 2015). Because several of the terms were frequently used as descriptors for other things than plus-size bodies, I manually removed any instances that did not refer to people and/or bodies from the concordance (e.g. "big fat cake"). Terms that were used to describe specific body parts (e.g. "fat thighs") were included in the analysis. ${ }^{8}$ However, I did not include any instances where a term was only used because it was a part of a proper name (e.g. the name of a clothing brand, such as Curvy Kate). Alternative spellings (e.g. plus-sized; plus size) and comparative and superlative forms were taken into account when counting the frequencies. Terms that referred to people who are not plus-size ("thin", "skinny"), as well as words that described physical attributes not related to weight or body shape ("short", "tall") were excluded from the analysis. ${ }^{9}$ Altogether 45 terms were analyzed (see Figure 3). As I will illustrate in Section 6, some of the terms were used by only one blogger, while others were used by most of the bloggers at some point in time.

In the analysis, I treat the blog posts and the comments published in the blogs' commenting sections as separate data-sets, or sub-corpora. The commenting section contains responses from the bloggers lips or eyelashes, but also as a descriptor for bodies in other types of posts. In the analysis, I included hits such as "designed for a fuller figure" but excluded hits such as "this lip gloss makes your lips appear fuller".$$
\text { It should be mentioned that the words used to describe the out-group are also relevant in terms of }
$$
identity construction. In the future, the present study could be expanded upon by analyzing body descriptors used for women who are not plus-size. 
as well as comments from visitors. Thus, it can be regarded as a "discussion" that takes place between the authors and their followers. Although many people that comment on blog texts are bloggers themselves, some of them only follow and comment on blogs without authoring their own blogs. Depending on the blog, the discussion may allow anonymous comments.

I classified the 20 bloggers into three categories based on the overall topic of the blog and/or the blogger's approach to writing about plus-size fashion (cf. Limatius, 2018). Fat activist bloggers (Blogs 1, 2, 4, 8, 11, 13, and 15) wrote about the sociopolitical aspects of being fat frequently and considered it important for fat people to gain more visibility in the (fashion) media. Fashionista bloggers (Blogs 3, 6, 9, 14, 16, 17, and 18) focused more on personal style and commenting on current fashion trends; while they occasionally addressed issues regarding the marginalization of fat people in fashion and in society, such commentary was not the main purpose of their blogs. Finally, all-rounder bloggers (Blogs 5, 7, 10, 19, and 20) blogged about a wider variety of topics ranging from photography to beauty products, and many of them had only recently focused their blogs on fashion. In the analysis, these categories are represented by the letters $\mathbf{A}$ (activist), $\mathbf{F}$ (fashionista), and $\mathbf{R}$ (all-rounder).

While the present study emphasizes quantitative data, the analytical method can be considered a mixed method; in addition to analyzing the frequency and distribution of the body descriptors used by the bloggers, I complement the analysis with qualitative examples from the blogs.

\section{Results}

In this section, I will present the results of the analysis. First, I will discuss the frequency and distribution of different descriptors in the corpus in general. Second, I will examine the role of the blogger categories (fat activists, fashionistas and all-rounders) in the use of body descriptors. Third, I will explore the differences between the two sub-corpora: blog posts and the commenting section discussions. Textual examples from the corpus are presented alongside the quantitative data. Bold text is used to highlight specific words in the examples.

\subsection{The frequencies of different body descriptors in the corpus}

Since there was variation in the overall number of words in each individual blog, the frequencies of terms were normalized to a common base on 10,000 words. As demonstrated by Figure 2 below, even after normalizing the frequencies, one blog - Blog 11 - is clearly different from the other nineteen. Blog 11 belongs to the fat activist category of bloggers and contains a lot of metadiscourse on the use of body-related terminology; for example, the author explicitly states why she prefers to describe herself using certain words and expresses her thoughts on words that she does not like:

Example 1: "It annoys me that, as a size 22-24 model, it would appear to some people that I should market myself an obese/fat model instead of as plus size." (Blog 11, A)

When discussing her modelling career, the author of Blog 11 expresses her annoyance at being called an "obese" or "fat" model, instead of the industry standard, which is "plus-size". No doubt the medical connotations of "obese" play into this, but interestingly enough, the blogger in question does not normally have a problem with the word "fat"; in fact, she uses it rather often, and even states her desire to normalize the word. Example 1 thus illustrates the importance of context - the blogger considers it unfair that she should have a different descriptor than smaller women in the context of plus-size fashion modelling. 
The type of metadiscursive commentary on body descriptors present in Example 1 naturally leads to the blogger using body descriptors relatively often. Blog 11 is the smallest blog in the corpus $(39,902$ words in posts and 12,693 words in comments), which makes the contrast between this particular blog and other blogs especially noticeable.

Figure 2: Aggregated standardised frequencies of body descriptors in different blogs

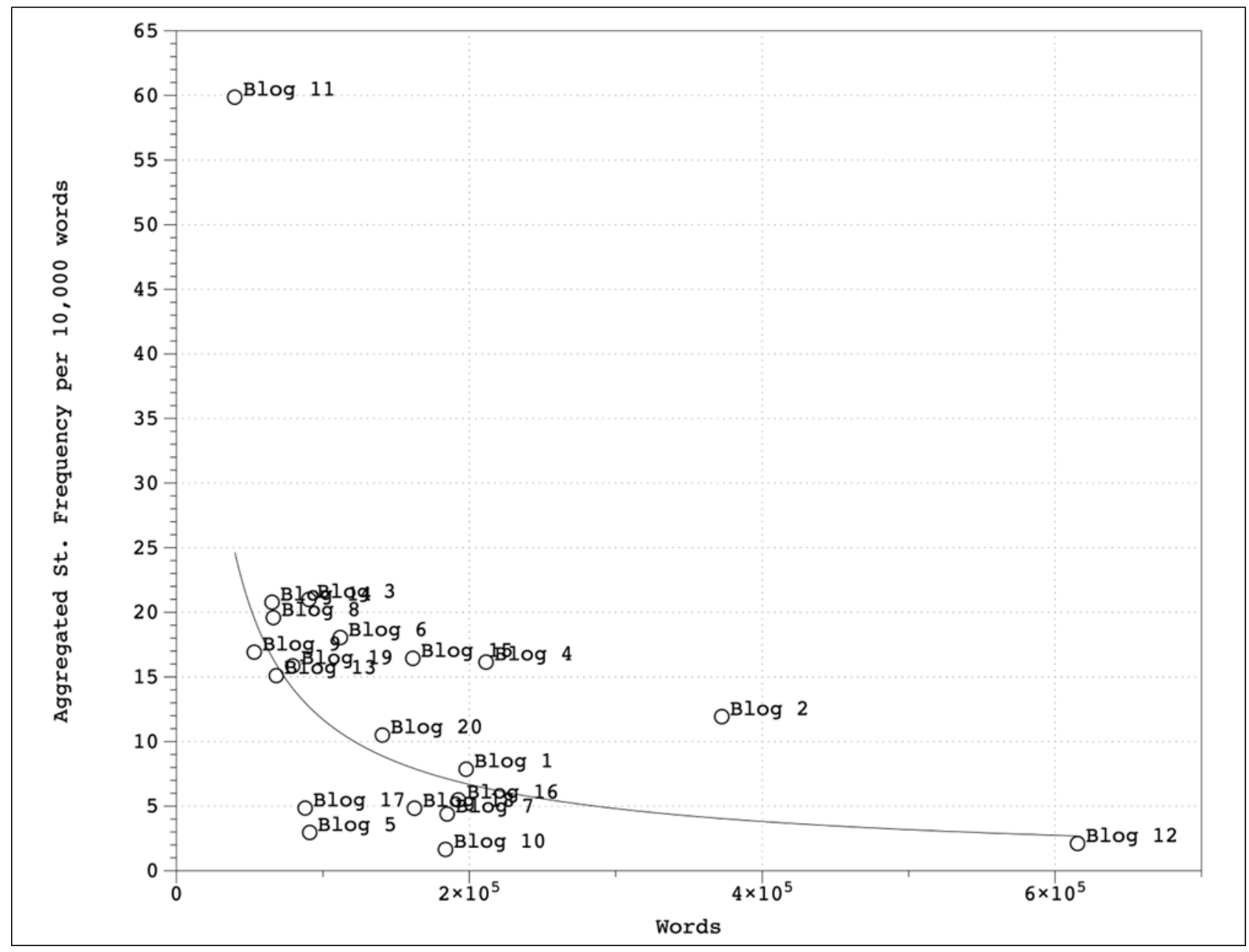

The standardised frequencies of all terms that appeared in blog posts are presented in Figure 3 below. Overall, "fat" was the most common term (mean standardised frequency 5.42), followed by "plus-size" (mean: 3.45), "big" (mean: 1.39) and "large" (mean: 0.89), with "curvy" completing the top five (mean: 0.49). As Figure 3 illustrates, the use of body descriptors in general was most common in the highly exceptional Blog 11 . If Blog 11 is not taken into account, the differences in the use of the terms become smaller, although the order in the top five - "fat", "plus-size", "big", "large", "curvy" - does not change. However, there are some terms that are clearly affected by the presence of Blog 11: "BBW" (an acronym of "big, beautiful woman") seems fairly popular in blog posts with a mean of 0.2 , but if Blog 11 is removed from the equation, the mean drops to 0.02 .

The least popular terms in blog posts were "boobilicious" and "stodgy" (mean: 0.0015), both of which were used only once (by the author of Blog 2), as well as "bootylicious", "rotund" and "booby", which were completely absent in the blog post sub-corpus. Thus, the least popular descriptors seem to be either creative word formations used by specific bloggers, or traditionally "unflattering" terms. "Bootylicious" most likely originates from the popular 2001 Destiny's Child 
song, while "boobilicious" is derived from the same term but used to refer to large breasts instead of a large "booty". Neither "rotund" nor "stodgy" can be considered as particularly flattering or witty words for describing the plus-size body, yet they are probably not common enough as insults to undergo the process of reappropriating a word with negative connotations, as in the case of "fat".

Example 2: "My hair's a bit bedraggled, my lipstick has worn off and I'm a bit stodgy after my tea, but my skin looks good and so do my lady lumps!" (Blog 2, A)

In Example 2, the blogger uses "stodgy" in reference to her state of being after eating, in a context where one might use, for example, "bloated". Yet, she finds that her skin and "lady lumps" still look good; thus, "stodgy" seems to describe a temporary view of the blogger's body, rather than a term she uses intentionally to construct her identity as a plus-size woman.

Figure 3: Distribution of terms in blog posts

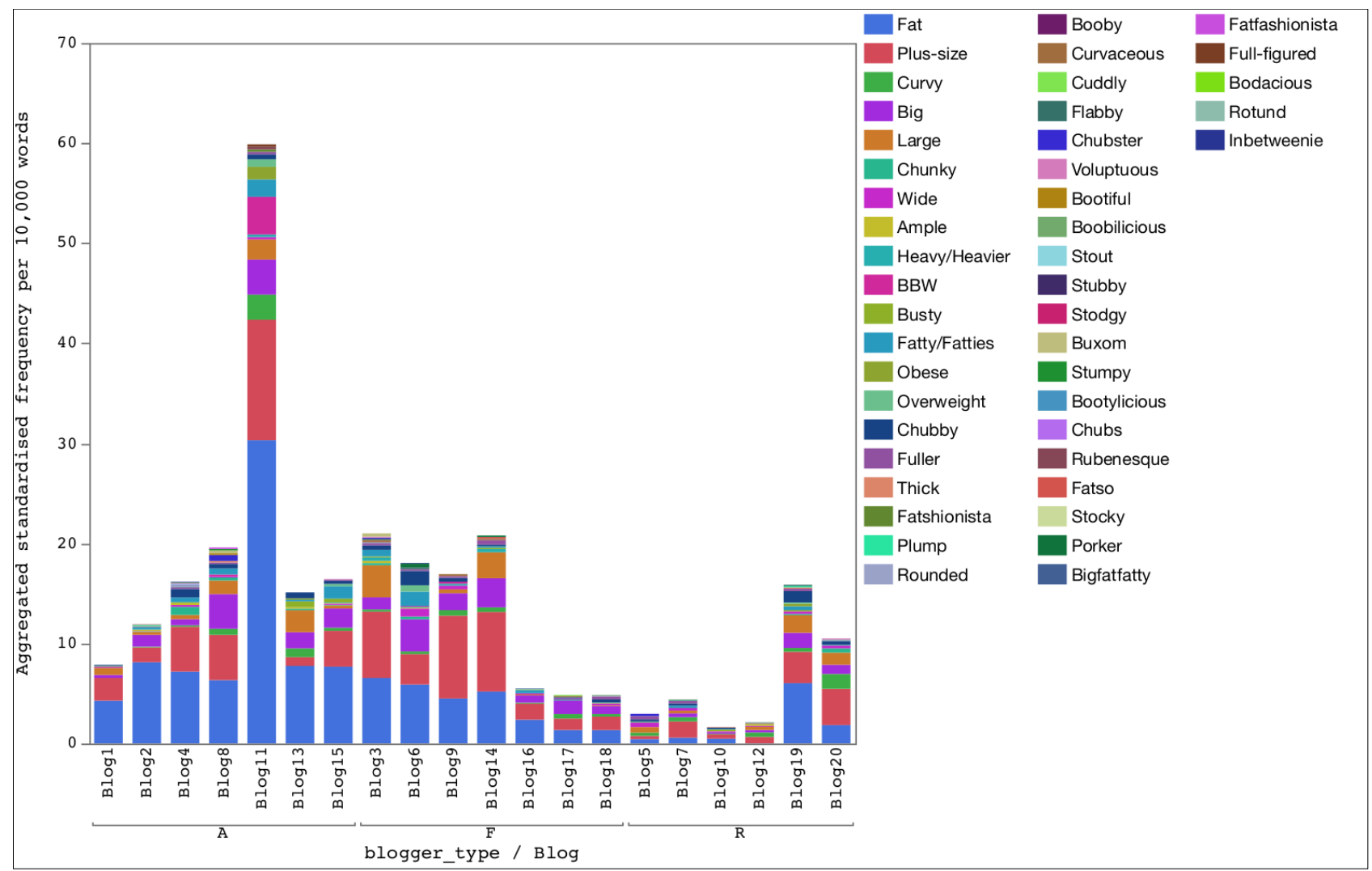

Several terms that were present in the blog post sub-corpus did not appear in the commenting section discussions. Altogether sixteen terms out of the 45 that were investigated were missing from the commenting section corpus. Again, these terms included creative word formations ("bigfatfatty", "inbetweenie", "boobilicious", "bootiful", "chubs", "fatfashionista") and words that have traditionally unflattering connotations ("fatso", "stocky", "stodgy", "stout", "stubby", "chubster"). In addition to these terms, "full-figured", "bodacious", "buxom", and "rubenesque" were missing from the commenting sections. The absence of the last set of terms might be explained simply by the fact that the terms in question are less commonly used in everyday language than, for example, "fat" or "plus-size". Another explanation could be that as peripheral members of the blogging community, the commenters have not adopted as wide a variety of descriptors as the bloggers. Moreover, since blog authors tend to be creative people with an 
appreciation for wit (see Limatius, forthcoming 2019), they are perhaps more likely to use colorful vocabulary.

Although the general trend is that body descriptors are more common in blog posts than in the commenting section discussions, there are some interesting exceptions. For example, the word "fat" was clearly more common in the commenting section of Blog 1 (standardised frequency of 24.99) than in the blog posts of the same blog (standardised frequency of 4.29). As can be seen from Figure 4 below, the frequencies of body descriptors in Blog 11 are not as exceptional when looking at the commenting sections; in fact, body descriptors are used more by commenters in Blogs 1 and 13 .

The top five most frequent terms are slightly different in the two sub-corpora. While "fat" (mean standardised frequency 5.28), "plus-size" (mean: 1.78) and "big" (mean: 1.07) make up the top three in the commenting section discussions, as they do in blog posts, "overweight" (mean: 0.62) is more common than either "large" (mean: 0.47) or "curvy" (mean: 0.46) in the commenting section corpus. However, this is mostly due to the fact that "overweight" appears rather frequently in the commenting section of Blog 13 (standardised frequency of 9.04).

If we do not take into account the terms that are completely absent in the commenting sections, the least popular terms in this sub-corpus are "stumpy", "bootylicious" and "rotund" (each with a standardised frequency of 0.001). Each of these three words only appeared once in the corpus. Interestingly, all three words were once again found in the commenting section of Blog 2. The author of Blog 2 appears to have a penchant for particularly colorful language, which might also affect the vocabulary used by her followers. Even though people who comment on blogs without authoring one themselves can be considered as peripheral members of the blogging community, the actual bloggers are likely to be looked up to and mimicked by the commenters because of their core membership (cf. Wenger, 1998; Holmes \& Meyerhoff, 1999, p. 174). 
Figure 4: Distribution of terms in commenting section discussions

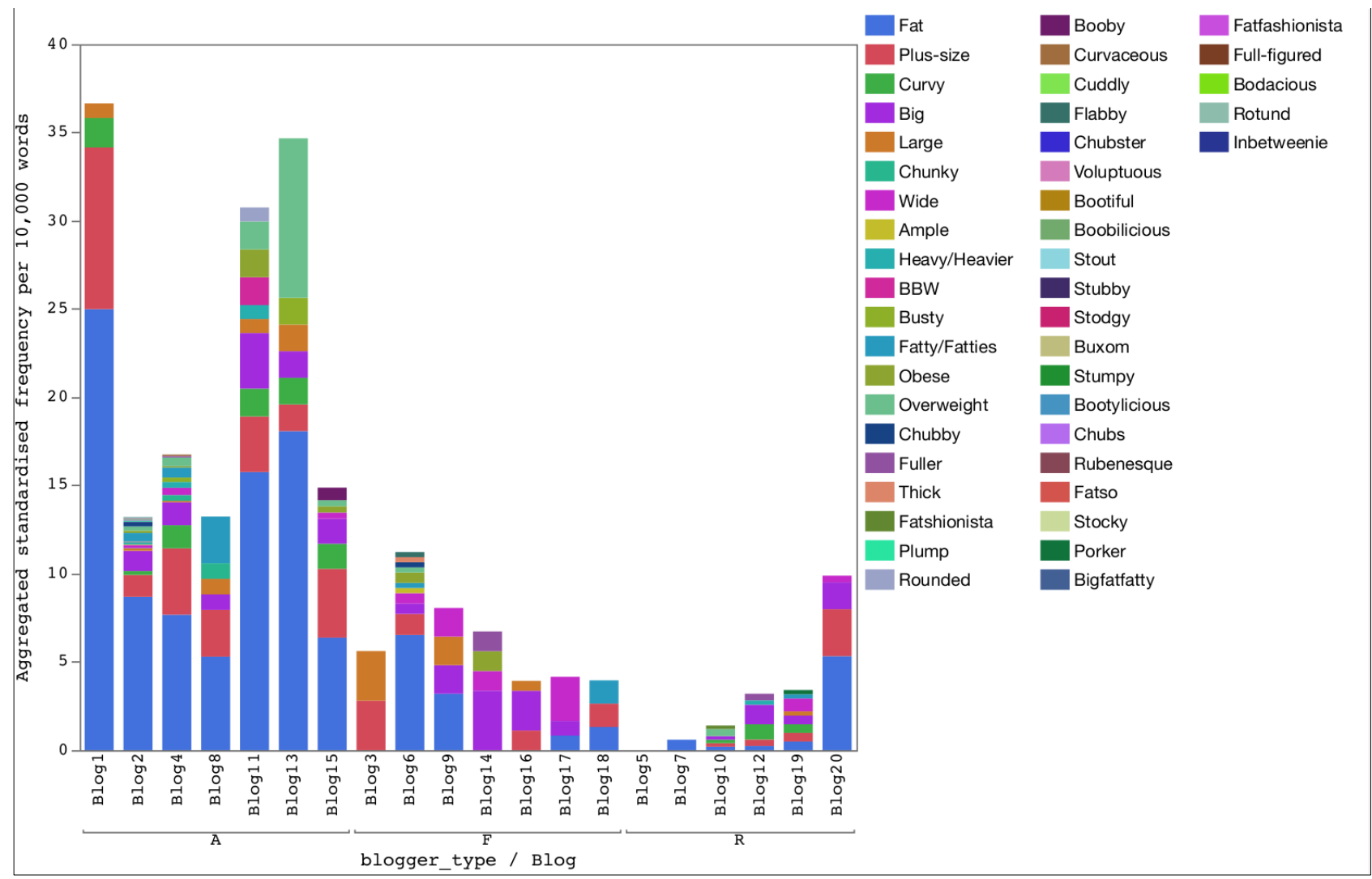

\subsection{The variation between different blogs and categories of bloggers}

As expected, the all-rounder bloggers use body descriptors in their blog posts less than fat activist or fashionista bloggers. ${ }^{10}$ The reason for this is the fact that the all-rounder blogs contain a wider variety of topics, which means that there are many posts where weight and body shape/size are not discussed. Unsurprisingly, "fat" is most frequently used among the fat activist bloggers, but when it comes to the use of the more neutral "plus-size", the difference between fat activist and fashionista bloggers is not very obvious (see Figure 5 below). $\mathrm{p}=0.018$ ). The difference between fashionistas and activists is not statistically significant (Mann-Whitney U-test: $Z=-$ $0.255, \mathrm{p}=0.79$ ). 
Figure 5: Terms in different blog categories (blog posts)

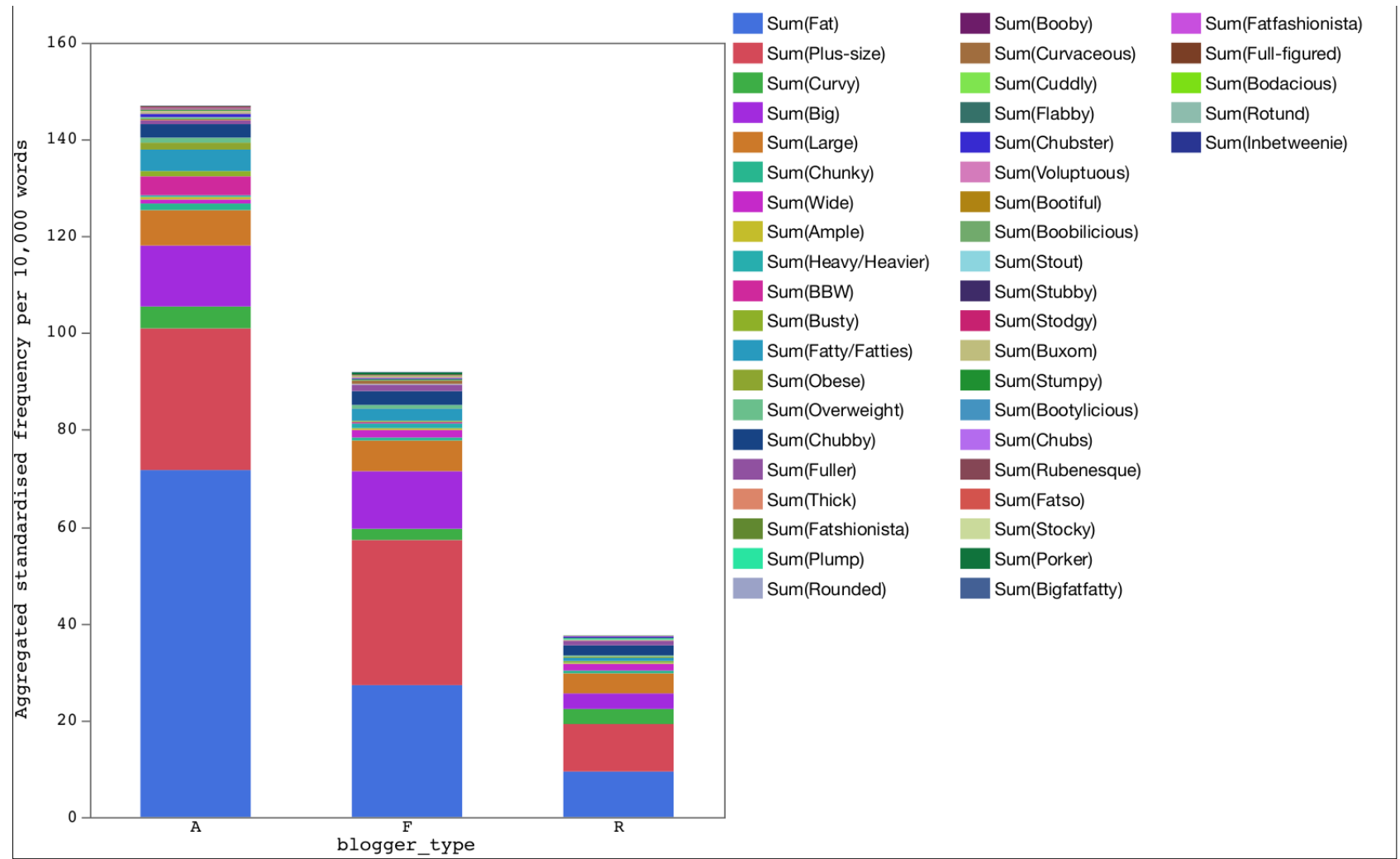

In the commenting section discussions, the difference between fat activist bloggers and the other categories becomes more pronounced, especially when it comes to the use of "fat" (see Figure 6 below). ${ }^{11}$ However, it should be noted that there are some fat activist bloggers, most notably the author of Blog 2, who respond to comments very actively. If the blog author uses a term frequently in their blog posts, it can be assumed that they use it when responding to comments as well. Thus, the differences in the use of descriptors in commenting section discussions are not only affected by what terms the readers use when commenting, but also the ways in which the author of the blog responds to comments. Whitney U-test: $Z=-2.92, p=0.003$ ), and fashionistas and activists (Mann-Whitney U-test: $Z=-3.06, p=0.002$ ). 
Figure 6: Terms in different blog categories (commenting section discussions)

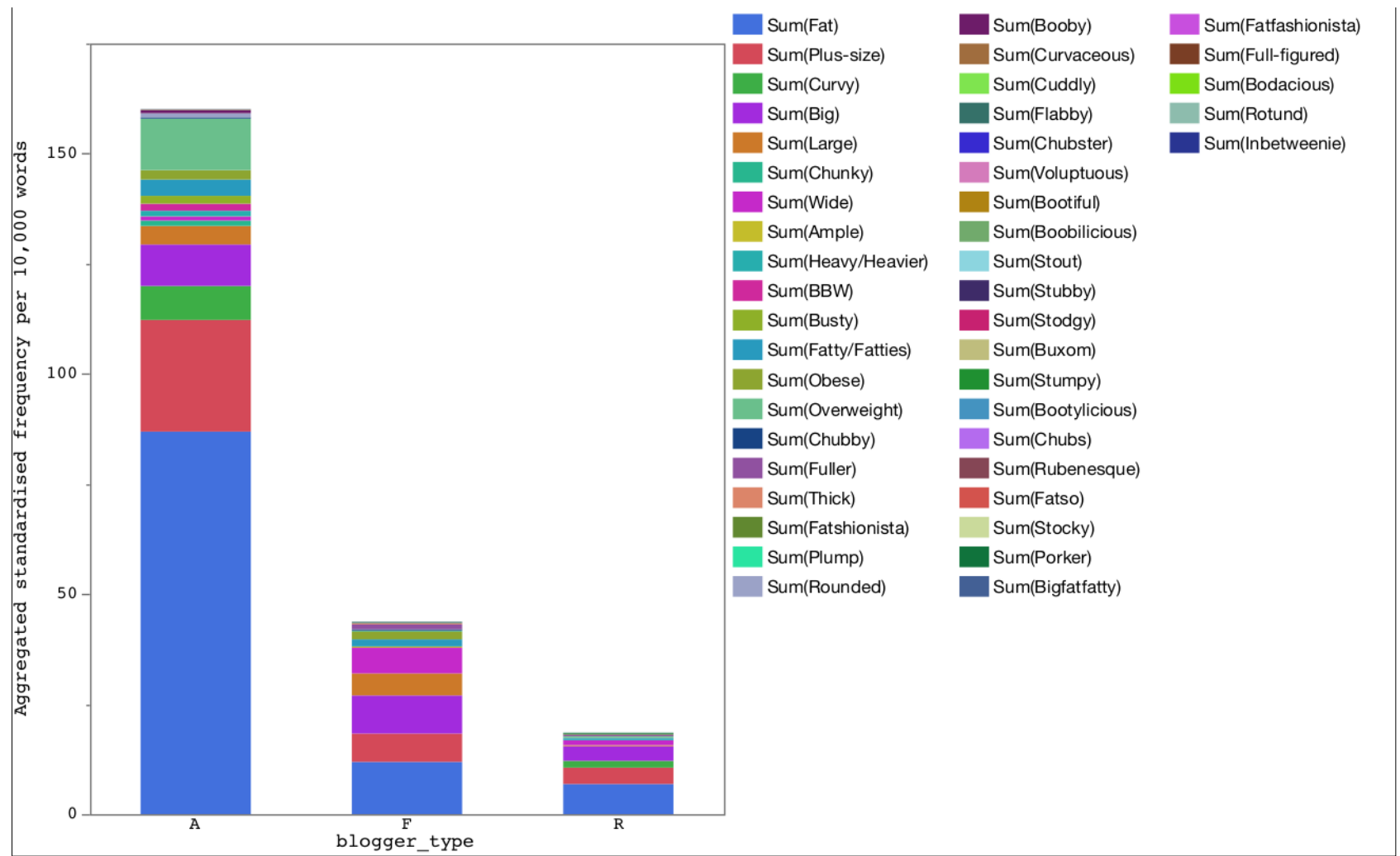

\subsection{Blog posts vs. comments}

As mentioned above, a wider variety of body descriptors was present in the blog post sub-corpus than in the commenting section discussion sub-corpus. Now I will examine the differences between the use of descriptors in the blog posts and in the commenting sections in more detail. 
Figure 7: The distribution of body descriptors between blog posts and commenting section discussions

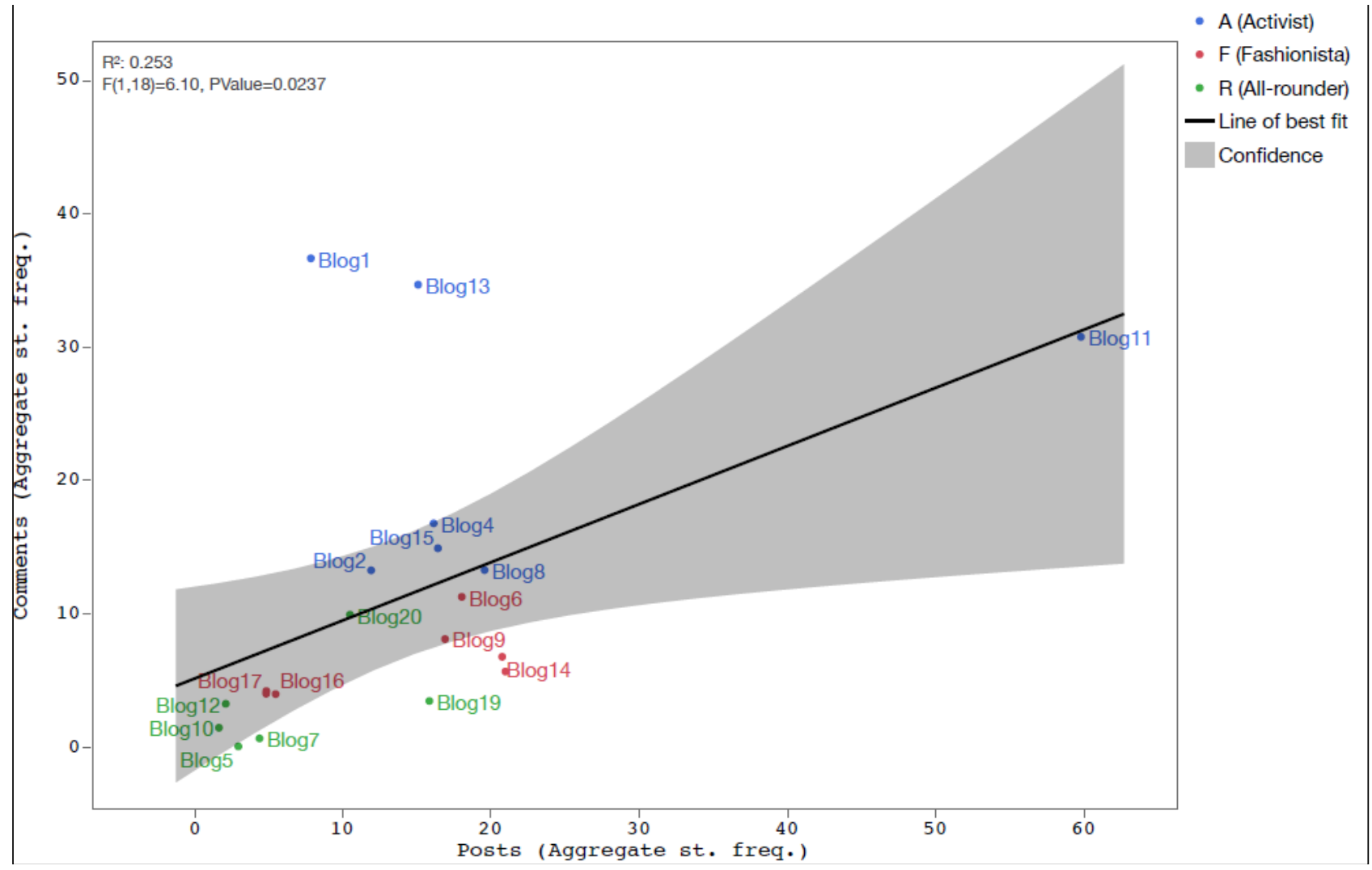

As Figure 7 above illustrates, there are notable differences in the amount of body descriptors found in the commenting section discussions of different blogs. The most occurrences of body descriptors are found in the commenting sections of blogs that belong to the fat activist category. The commenters of fat activist blogs clearly use body descriptors more than the commenters of fashionista and all-rounder blogs. These results further imply that people who read fat-acceptancefocused blogs have adopted the use of in-group terminology, such as the reappropriated "fat"; it could be that the using a variety of body descriptors has become a part of the shared repertoire of a kind of micro-community of fat activist bloggers (although, as mentioned before, the results are also affected by the response comments of the authors themselves).

Special attention should be payed to Blogs 1 and 13 here; in these blogs, the commenting section discussions feature more body descriptors than the actual blog posts. This is especially apparent when we look at some of the more popular terms in detail: for the word "fat", the standardised frequency is 4.39 in the blog posts of Blog 1, while the stardardised frequency of the same word is 24.99 in the commenting section of Blog 1. In Blog 13, "overweight" does not occur in the blog posts at all, but it has a standardised frequency of 9.04 in the commenting section. A qualitative investigation of the occurrences of "overweight" in the commenting section of Blog 13 reveals that commenters appear to view the term as a "neutral" descriptor:

Example 3: "I think this doctor lacks sympathy and is being lazy lumping all your issues under the umbrella of being overweight." (Comment in Blog 13, A)

The comment in Example 3 is from a blog post where the author of Blog 13 discusses her health; mental health in particular. It is notable that the blogger refers to herself as "fat" in the title of the 
post, but the commenter criticizes the blogger's doctor for "lumping all [her] issues under the umbrella of being overweight".

Blog 11 also continues to be somewhat exceptional. As we saw earlier in Figure 2, the small size of the blog and the extensive metadiscursive discussion on the appropriateness of specific body descriptors result in elevated numbers in the relative frequency of such descriptors. However, as Figure 7 illustrates, Blog 11 does not stand out as much when we only compare the frequencies of body descriptors in the commenting sections. Even though the frequencies are still high when compared to most of the other blogs (especially those in fashionista and all-rounder categories), body descriptors are more frequent in the commenting sections of Blogs 1 and 13 (and the other fat activist blogs are not far behind). This further highlights the fact that it is the author of Blog 11 who uses body descriptors particularly often; the use of these terms by the audience is not as frequent.

When considering the role of body descriptors in identity construction, the metadiscursive commentary in Blog 11 requires qualitative analysis. Even though a word occurs relatively often, it does not mean the author of Blog 11 identifies with or endorses the use of the term in question (cf. Example 1). The use of "curvy" is a good example of such occurrences:

Example 4: "I'm bottom heavy but I'm not curvy, meaning my body shape isn't in the 'good fat' or 'popular' demographic.” (Blog 11, A)

Example 5: "...I can tell you what not to say...for the love of all things please do NOT say that I'm curvy." (Blog 11, A)

In Examples 4 and 5, the author of Blog 11 uses "curvy" as a body descriptor but underlines the fact that she personally does not fit that description, nor does she want to be referred to as "curvy". She criticizes the term by mentioning its association with so-called "good fat" bodies, meaning voluptuous, pin-up style "hourglass" shaped bodies (cf. Harju and Huovinen, 2015; Afful \& Ricciardelli, 2015, p. 15) that are considered socially acceptable and attractive. However, it should be noted that the same blog also contains mentions of "curvy" in a positive or neutral context:

Example 6: "And you are curvy, you just have curves in different places to others!!" (Comment in Blog 11, A)

The commenter in Example 6 questions the blogger's definition of "curvy", suggesting that bodies with all types of "curves" could be described by the term, including those that do not confirm to the "hourglass" stereotype. Blog authors and commenters can have differing views on the meanings associated with particular body descriptors, and as is typical of a community of practice, these meanings can also change through a process of learning and mutual interaction.

\section{Discussion and conclusion}

The corpus-linguistic analysis of body descriptors reveals that plus-size fashion bloggers use a wide range of terms to describe plus-size bodies in their online discussions. However, a number of these terms, especially creative word formations, are only used by specific bloggers, whereas more established terms like "fat" and "plus-size" are (with minor exceptions) fairly popular across the board. 
Qualitative examination of the data reveals that for the most part, "fat" is used by the bloggers and commenters as a descriptor purposefully and with no derogatory intent. Thus, it can be tentatively concluded that the plus-size blogging community has reappropriated the word:

Example 7: "I've never bothered hiding the fact I'm a fat bird and I just don't care." (Comment in $\mathrm{B} \log 4, \mathbf{A})$

However, there were also a few instances where "fat" was used in a context where its traditionally derogative connotations could be detected:

Example 8: "My Mum is the type of mum who makes your friends want her for their own, she's the type that doesn't judge you, that you can talk to like a sister, who doesn't force you to do something that doesn't make you happy, and tells you straight away if a dress does make you look fat." (Blog 7, R)

Even though the author of Blog 7 does not explicitly say being fat is a bad thing, the implication is that one does not want to wear a dress that makes one "look fat", and that telling a person this can be considered doing them a favor.

While the overall frequency of "fat" appears to support the claims made in previous studies about the reappropriated use of the term, the influence of fat activist blogs is clear here. In fact, "plussize" is slightly more popular in the other two categories, and there were also bloggers who used "fat" very rarely, such as the author of Blog 12 (all-rounder category).

The fact that "plus-size" is more common than "fat" in the more fashion-focused blogs also reflects the reality of the plus-size fashion industry; while bloggers may have reappropriated "fat", clothing companies continue to play it safe by relying on more neutral, traditionally flattering terms. Words like "curves" and "curvy" are still often found in the names of clothing ranges for plus-size women. These terms have connotations to the "good" kind of fat that is presumed to make a woman's body sexually appealing - full breasts and hips, narrow waist - and are thus more attractive to businesses. Interestingly, the results of the present study illustrate that "curvy" is considerably less popular than "plus-size" or "fat" among bloggers. If bloggers are seen to represent the "average" plus-size woman, there appears to be a dissonance between the consumers' identity and the identity categories presented to them by the fashion industry. However, that is a topic that requires further research.

As for the benefits of the corpus-linguistic approach, Blog 11 (fat activist category) serves as a good example of the usefulness of combining methods. A case study focusing around Blog 11 would have produced rather different results than the present study, as the size of the blog and the author's penchant for metadiscursive discussion on terminology have a notable effect on the relative frequency of body descriptors. On the other hand, as shown in section 6.3, a qualitative investigation of Blog 11 reveals features that might have been overlooked in a purely quantitative study, such as the fact that body descriptors are also used when dissociating oneself from a particular identity category.

The comparison between the blog post and commenting section sub-corpora also reveals some interesting findings. Overall, the commenters of fat activist blogs appear to use body descriptors actively. There are several possible reasons for this. Firstly, it can be theorized that if a blogger uses specific linguistic features often, their readers will start to use them as well to show solidarity and to express a sense of shared identity with the blogger - they are learning the "rules" of the community 
of practice. However, as in the case of Blog 1, sometimes the commenting section contains more body descriptors than the actual post texts of the blogs. It could be that people who read fatacceptance-influenced blogs, and comment on them actively, are more likely to use body descriptors in general. Afful and Ricciardelli $(2015$, p. 4) refer to the process of fat acceptance activists "coming out" as fat on their blogs by making themselves visible in a context where they have previously been invisible, such as fashion. The readers of fat activist blogs may have already "come out" and are now looking for resources for expressing their identity by reading and commenting on blogs, even if they do not write blogs themselves.

When addressing the differences between the commenting section discussions, we should keep in mind that the commenting section discussions also contain comments by the blogger herself. In the present study, these we not treated as a separate data-set, but it would be interesting to do so in the future to see whether fat activist bloggers communicate with commenters more actively than other categories of bloggers. In the present study, both the blog posts and comments in Blog 2 featured a variety of terms that were not used in other blogs. This is probably affected by the fact that the author of Blog 2 appears to respond to comments actively, but it is also possible that her habit of using a wide range of descriptors has affected the language of her readers. Although bloggers consider responding to comments important (Limatius, forthcoming 2019), they do this to different extents, with some bloggers responding to every comment, and others only addressing concerns or questions presented by the commenters. A more detailed study of the commenting section discussions could provide new information on blogs as interactive communities of practice, and the roles that different actors have within these communities.

In regard to identity construction, both the fact that "fat" is the most commonly used descriptor in the corpus as a whole, and the fact that there still exists such a wide variety of other terms that different bloggers use are interesting. Of course, the evidence of variety could imply that not all plus-size women have reappropriated "fat", and that some still see it as a negative term. However, a more optimistic interpretation is also possible; removing "fat" from its traditionally negative connotations has perhaps been merely the first phase of the "revolution that replaces the spoiled identity of fatness" (LeBesco, 2001, p. 76). The next step could be extending this empowering process of reappropriation to other terms. In the corpus, we can see hints of progress to this direction - in Example 9, different terms are listed as equally valid ways of describing a plus-size person's size:

Example 9: "I am plus size; fat, curvy, big, heavy, plump, chubby... however you want to put it is fine by me." (Blog 20, R)

The present study of body descriptors used by plus-size fashion bloggers has highlighted the fact that corpus-based approaches can complement qualitative studies of online discourse. In the future, similar methodological combinations could also provide new perspectives into the online interaction of other marginalized groups. 


\section{References}

Afful, A. A., Ricciardelli, R., 2015. Shaping the online fat acceptance movement: Talking about body image and beauty standards. Journal of Gender Studies, http://dx.doi.org/10.1080/09589236.2015.1028523

Allan, K., 2015. When is a slur not a slur? The use of nigger in 'Pulp Fiction'. Language Sciences 52: 187-199. https://doi.org/10.1016/j.langsci.2015.03.001

Anthony, L., 2015. AntConc (Version 3.4.4) [Computer Software]. Waseda University, Tokyo. http://www.laurenceanthony.net/

Bourlai, E.E., 2018. 'Comments in tags, please!': Tagging practices on Tumblr. Discourse, Context \& Media 22, 46-56.

Connell, C., 2013. Fashionable resistance: Queer "fa(t)shion" blogging as counterdiscourse. Women's Studies Quarterly 41 (1/2), 209-224.

Dickins, M., Thomas, S. L., King, B., Lewis, S., Holland, K., 2001. The role of the fatosphere in fat adults' responses to obesity stigma: A model of empowerment without a focus on weight loss. Qualitative Health Research 21 (12), 1679-1691.

Downing Peters, L., 2014. You are what you wear: How plus-size fashion figures in fat identity formation. Fashion Theory 18 (1), 45-72. https://doi.org/10.2752/175174114X13788163471668.

Drasovean, A., Tagg, C., 2015. Evaluative language and its solidarity-building role on TED.com: An appraisal and corpus analysis. Language@Internet 12, article 1.

https://www.languageatinternet.org/articles/2015/drasovean (accessed 11 July, 2019)

Eckert, P., McConnell-Ginet, S., 1992. Think practically and look locally: Language and gender as community-based practice. Annual Review of Anthropology 21, 461-490.

Gurrieri, L., Cherrier, H., 2013. Queering beauty: Fatshionistas in the fatosphere. Qualitative Market Research: An International Journal 16 (3), 276-295.

Harju, A., Huovinen, A., 2015. Fashionably voluptuous: normative femininity and resistant performative tactics in fatshion blogs. Journal of Marketing Management 31 (15-16), 1602-1625.

Harjunen, H. (2009). Women and fat: Approaches to the social study offatness. Jyväskylä: Publishing Unit, University Library of Jyväskylä.

Hartley, C. 2001. Letting ourselves go: Making room for the fat body in feminist scholarship, in Braziel, J.E.; LeBesco, K. (Eds.), Bodies out of bounds: Fatness and transgression. University of California Press, Berkley, pp. 60-73.

Holmes, J., Meyerhoff, M. 1999. The community of practice: Theories and methodologies in language and gender research. Language and Society 28 (2), 173-183. 
Ivković, D., 2013. The Eurovision Song Contest on YouTube: A corpus-based analysis of language attitudes.Language@Internet 10, article 1.

https://www.languageatinternet.org/articles/2013/Ivkovic (accessed 6 March 2019).

Kehoe, A., Gee, M., 2012. Reader comments as an aboutness indicator in online texts: Introducing the Birmingham Blog Corpus. In S. Oksefjell Ebeling, J. Ebeling, H. Hasselgård (Eds), Studies in Variation, Contacts and Change in English volume 12: Aspects of Corpus Linguistics: Compilation, Annotation, Analysis. University of Helsinki e-journal.

http://www.helsinki.fi/varieng/series/volumes/12/kehoe_gee/ (accessed 6 March 2019)

Kelsey, M., 2009. Queer slang and negative identity: How GLBT individuals own and reject homophobic slang. In B.E. Drushel, K.E. German (Eds.) Queer Identities / Political Realities. Cambridge Scholars Publishing, Newcastle upon Tyne, pp. 155-179.

Lave, J., Wenger, E., 1991. Situated Learning: Legitimate Peripheral Participation. Cambridge: Cambridge University Press.

LeBesco, K., 2001. Queering fat bodies/politics. In J.E. Braziel, K. LeBesco (Eds.), Bodies out of bounds: Fatness and transgression. University of California Press, Berkeley, pp. 74-87.

Lehti, L., Laippala, V., 2014. Style in French politicians' blogs: Degree of formality. Language@Internet 11, article 1. http://www.languageatinternet.org/articles/2014/lehti/ (accessed March 6 2019).

Limatius, H., 2017. "There really is nothing like pouring your heart out to a fellow fat chick": Constructing a body positive blogger identity in plus-size fashion blogs, Token: A Journal of English Linguistics 6, 23-49.

Limatius, H., 2018. Fat, curvy or plus-size? A corpus-linguistic approach to identity construction in plus-size fashion blogs." In: Juntunen, H., Sandberg, K., Kocabas, K., (Eds.), In Search of Meaning: Literary, Linguistic, and Translational Approaches to Communication, Tampere University, pp. 1238 .

Limatius, H., forthcoming 2019. "We portray OURSELVES": The empowerment potential of fashion blogging for plus-size women, Neuphilologische Mitteilungen.

Lukač, M., 2011. Down to the bone: A corpus-based critical discourse analysis pro-eating disorder blogs. Jezikoslovlje 12(2): 187-209.

Lutzky, U., Kehoe, A., 2017. "I apologize for my poor blogging": Searching for apologies in the Birmingham Blog Corpus. Corpus Pragmatics 1: 37-56. https://doi.org/10.1007/s41701-017-0004-0

Lutzky, U., Kehoe, A., 2016. Your blog is (the) shit: A corpus-linguistic approach to identification of swearing in computer mediated communication. International Journal of Corpus Linguistics 21 (2), 165-191.

McDonald, D., Woodward-Kron, R., 2016. Member roles and identities in online support groups: Perspectives from corpus and systemic functional linguistics. Discourse \& Communication 10 (2), 157-175.

Mattiello, E., 2018. A corpus-based analysis of scientific TED Talks: Explaining cancer-related topics to non-experts. Discourse, Context \& Media, https://doi.org/10.1016/j.dcm.2018.09.004. 
Rocamora, A., 2011. Personal fashion blogs: Screens and mirrors in digital self-portraits. Fashion Theory 15 (4), 407-424.

Sastre, A., 2014. Towards a radical body positive: Reading the online 'body positive' movement. Feminist Media Studies 14 (6), 929-943.

Scaraboto, D., Fischer, E., 2013. Frustrated fatshionistas: An institutional theory perspective on consumer quests for greater choice in mainstream markets. Journal of Consumer Research 39 (6), 1234-1257.

Sifianou, M., 2015. Conceptualizing politeness in Greek: Evidence from Twitter corpora. Journal of Pragmatics 86, 25-30. https://doi.org/10.1016/j.pragma.2015.05.019

Titton, M., 2015. Fashionable personae: Self-identity and enactments of fashion narratives in $\begin{array}{llllll}\text { fashion } & \text { blogs. } & \text { Fashion } & \text { Theory } & 19 & \text { (2), }\end{array}$ https://doi.org/10.2752/175174115X14168357992391

van der Bom, I., Paterson, L.L., Peplow, D., Grainger, K., 2018. 'It's not the fact they claim benefits but their useless, lazy, drug taking lifestyles we despise': Analysing audience responses to Benefits Street using live tweets. Discourse, Context \& Media 21, 36-45.

Wenger, E., 1998. Communities of practice: Learning, meaning and identity. Cambridge University Press, Cambridge.

Zappavigna, M., 2014. Coffee tweets: bonding around the bean on Twitter, in Seargeant, P., Tagg, C. (Eds.), The language of social media: Identity and community on the Internet. Palgrave Mcmillan UK, 139-160. https://doi.org/10.1057/9781137029317. 